\title{
Investigation on the Current Situation of Reuse of the Exterior Windows of the Modern Complex in Zhongshan Square, Dalian
}

\author{
Shen Tianjiao, ${ }^{1, *}$ \\ ${ }^{1}$ Civil and Architectural Engineering, University of Jinan, Shizhong District, Jinan City, Shandong Province, PRC
}

\begin{abstract}
Exterior windows are architectural details with decoration, lighting and ventilation. By studying the current situation of the reuse of the exterior windows of the modern complex and making a survey of several representative windows, this paper analyzes and finds that the reuse of buildings in this area is quite different, but the overall situation is relatively good. The purpose of this investigation is to explore the advantages and disadvantages of the methods of reuse, in order to find a way that can realize the balance between the man and buildings.
\end{abstract}

\section{Introduction}

As a city under the colonial rule of Russia and Japan successively, Dalian has obvious western-style architecture. The building group of Zhongshan Square is a typical one among them. Different from historical blocks, the modern buildings of Zhongshan Square are mainly large public buildings with complex architectural styles, which can be described as a collection of Western Classicism. The exterior window, as a kind of architectural detail, plays an important role in representing in microcosm the style of the building group as a whole. Under unified protection and repair, most of the main buildings are in good condition. However, as one of the main structures of thermal insulation, the exterior window has suffered great damage. Therefore, only by studying the current situation of reuse of building exterior windows and discovering existing problems, can we find ways to maintain and use exterior windows scientifically to achieve a balance between people and buildings.

\section{Situation of Historical Development}

At first, Dalian was just a small fishing village in Northeast China. Then after the rule of Russia and Japan, the urban form developed at an amazing speed, thus forming one of the typical western cities in the history of China's modernization. In 1898, Russia sought a breakthrough in maritime trade, hoping to open up the Siberian Railway to the Pacific estuary trade. Therefore, it leased the southern part of the Liaodong Peninsula, which is now Dalian, and began to build a city. The center of the city it designed was Dalini, which is now the Zhongshan Square area. Dalini imitated the planning of Paris, France, took the circular square as the center, where was also the rudiment of Zhongshan Square. At the beginning of 1904, due to the outbreak of the Russo-Japanese War, Dalini's construction was also forced to stop. After the RussoJapanese War, the Japanese, as the new rulers, continued the urban planning of tsarist Russia, and the modern buildings of Zhongshan Square were gradually built here ${ }^{[1]}$. The buildings of Zhongshan Square, which have been ruled for several times, are not only a window of Dalian's urban construction history, but also a historical legacy of Dalian.

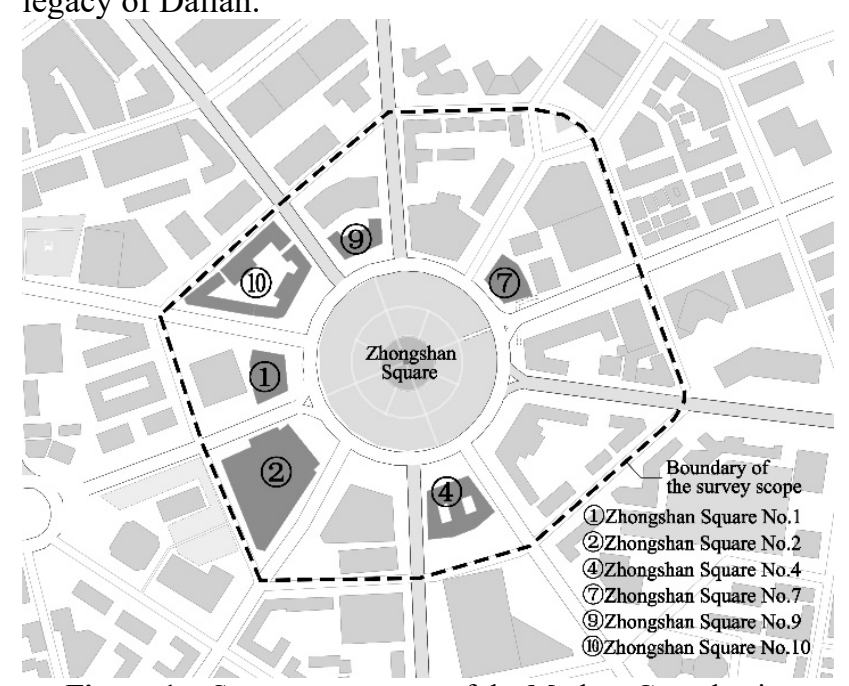

Figure 1. Survey scope map of the Modern Complex in Zhongshan Square

After several renovations, the remaining buildings with historical value now include the following 9 buildings: Zhongshan Square No.1 (used to be Bank of Korea, but it's Zhongshan branch of ICBC now), Zhongshan Square No.2 (used to be Dalian Civil Affairs Administration, but it's Liaoyang Bank now), Zhongshan Square No.4 (used to be Dahe Hotel, but it's Dalian Hotel now), Zhongshan Square No.5 (used to be Dahe Hotel, but it's Municipal Hall of Dalian now), Zhongshan Square No.6 (used to be Toyo Takushoku Co., Ltd., but it's Communication Bank of China now), Zhongshan Square No.7 (used to be TA Ching Government Bank, but it's

*Corresponding author: 986295326@qq.com 
CITIC Bank now), Zhongshan Square No.8 (it's People's Cultural Club now), Zhongshan Square No.9 (used to be Yokohama Shokin Bank, but it's Dalian branch of BOC now), Zhongshan Square No.10 (used to be Kanto Metropolitan Government Post and Telecommunications Bureau, but it's Dalian Post and Telecommunications Bureau now). The above buildings were listed as the fifth batch of national key cultural relics protection units by the State Council in 2001.

The building group of Zhongshan Square is a complex of many western architectural styles, and its exterior windows are one of the architectural details that represent the architectural style. As a detail with decorative and structural functions, exterior windows not only enrich the shape of the building, but also improve the cultural quality of the buildings partly. These exterior windows carry Dalian's nearly 100-year colonial history and demonstrate the humanistic spirit of the past era, which are precious. However, with the passage of time, the function of the building is iterated. In order to meet people's functional needs, the exterior windows have been also demolished and rebuilt. In addition, in the process of using for many years, many problems have appeared, and the needs of residents gradually conflict with the preservation of historical buildings. The purpose of our research is not only to understand the situation of its reuse, but also to explore a metric that can achieve a balance between people and buildings.

\section{Status of Windows' Reuse of Building Group}

Through the investigation of 9 buildings, the reuse situation of the whole buildings is relatively good. However, the reuse situations of the exterior windows of the buildings vary greatly among different building units, but present in a good way.

Table1. Reuse status of windows

\begin{tabular}{|c|c|c|c|}
\hline Building name & $\begin{array}{c}\text { Modern } \\
\text { windows }\end{array}$ & $\begin{array}{c}\text { Old } \\
\text { windows }\end{array}$ & $\begin{array}{c}\text { Additions of } \\
\text { appendage }\end{array}$ \\
\hline $\begin{array}{c}\text { Zhongshan } \\
\text { Square No.1 }\end{array}$ & $95 \%$ & $5 \%$ & ++++ \\
\hline $\begin{array}{c}\text { Zhongshan } \\
\text { Square No.2 }\end{array}$ & $100 \%$ & $/$ & ++++ \\
\hline $\begin{array}{c}\text { Zhongshan } \\
\text { Square No.4 }\end{array}$ & $1 \%$ & $99 \%$ & + \\
\hline $\begin{array}{c}\text { Zhongshan } \\
\text { Square No.7 }\end{array}$ & $95 \%$ & $5 \%$ & ++ \\
\hline $\begin{array}{c}\text { Zhongshan } \\
\text { Square No.9 }\end{array}$ & $100 \%$ & $/$ & + \\
\hline $\begin{array}{c}\text { Zhongshan } \\
\text { Square No.10 }\end{array}$ & $100 \%$ & $/$ & ++++++ \\
\hline As for the exteris
\end{tabular}

As for the exterior window decoration frames, among the 9 buildings in the survey, 5 of them have about $90 \%$ of the renovation part. 2 buildings have been renovated, accounting for less than $50 \%$, while only 2 buildings have not been renovated. As for the windows themselves, only Zhongshan Square No.4 (it's Dalian hotel now) of the 9 buildings surveyed has not been renovated. In the renovated exterior windows, it was found that most of the exterior decorative frames were sprayed with rock varnish, latex paint and other paint. However, the integration of modern paint and original building materials are not good. And improper maintenance measures in the later period also caused most of the decorative frames to be damaged and fall off. Aluminum alloy, plastic steel and other materials replaced the original wood and stone in the process of reuse, which greatly destroyed the original architectural style.

Table2. Reuse status of the exterior window decoration frames

\begin{tabular}{|c|c|c|}
\hline Building name & $\begin{array}{c}\text { Renovated } \\
\text { frames }\end{array}$ & $\begin{array}{c}\text { Unrenovated } \\
\text { frames }\end{array}$ \\
\hline $\begin{array}{c}\text { Zhongshan Square } \\
\text { No.1 }\end{array}$ & $90 \%$ & $10 \%$ \\
\hline $\begin{array}{c}\text { Zhongshan Square } \\
\text { No.2 }\end{array}$ & $90 \%$ & $10 \%$ \\
\hline $\begin{array}{c}\text { Zhongshan Square } \\
\text { No.4 }\end{array}$ & $95 \%$ & $5 \%$ \\
\hline $\begin{array}{c}\text { Zhongshan Square } \\
\text { No.7 }\end{array}$ & $80 \%$ & $20 \%$ \\
\hline $\begin{array}{c}\text { Zhongshan Square } \\
\text { No.9 }\end{array}$ & $60 \%$ & $40 \%$ \\
\hline $\begin{array}{c}\text { Zhongshan Square } \\
\text { No.10 }\end{array}$ & $90 \%$ & $10 \%$ \\
\hline
\end{tabular}

\section{Analysis of the Reuse of Exterior Windows in Different Buildings}

Affected by the structure and style of the building itself, there are great differences in the reuse status of exterior windows between different buildings. Some of them are successful cases, while others completely destroy the original architectural style. The following is the specific directions and methods for the reuse of exterior windows through the reuse of exterior windows in different buildings.

\subsection{Zhongshan Square No.1}

Zhongshan Square No.1 is one of the representatives of modern buildings in Zhongshan Square. Although it is one of the earlier buildings, the exterior windows are wellprotected, and the typical architectural details of ancient Rome are well preserved. 


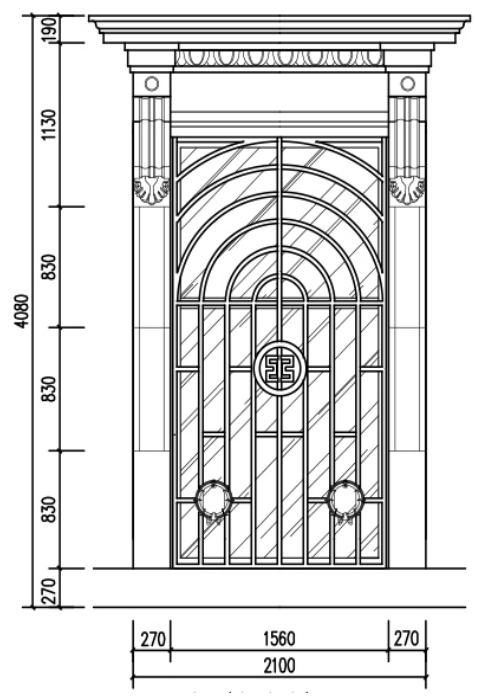

Figure 2. One of the exterior windows of Zhongshan Square No. 2

In the process of reuse, Zhongshan Square No. 1 is mainly updated in its functions, and its decorative frame is not changed much. According to the investigation on the use of the building's exterior windows, it is found that the original windows are replaced by modern windows, which perform very well in terms of thermal insulation so that people's life quality in the building is improved. For old buildings, this kind of exterior window modification can be said to be very important. At the same time, the original casement windows were changed into fixed windows to meet the needs of bank security function on the basis of not affecting the building facade.

The pillars, pediments and eaves moldings of the ancient Roman-style exterior windows are the main expressions of decoration, and the exterior windows also reflect this characteristic. The original decorative eaves moldings and pediments are well preserved, and the details of the patterns are clearly visible. Therefore, they are not changed in the reuse process, but the original surface of stone is sprayed with rock varnish (a kind of paint imitating the surface of stone).

However, the study found that the secondary update of the exterior window of Zhongshan Square No. 1 was incomplete. The different frame colors of plastic steel windows that updated for the first time and aluminum alloy windows for the second time affect the integrity of the entire facade. Through on-the-spot investigation, it was found that the plastic steel windows that have not been replaced are used in some idle rooms such as basements. Although these windows have a small proportion of the facade, they all can be seen clearly, which greatly affects the overall facade style of the building.

\subsection{Zhongshan Square No.2}

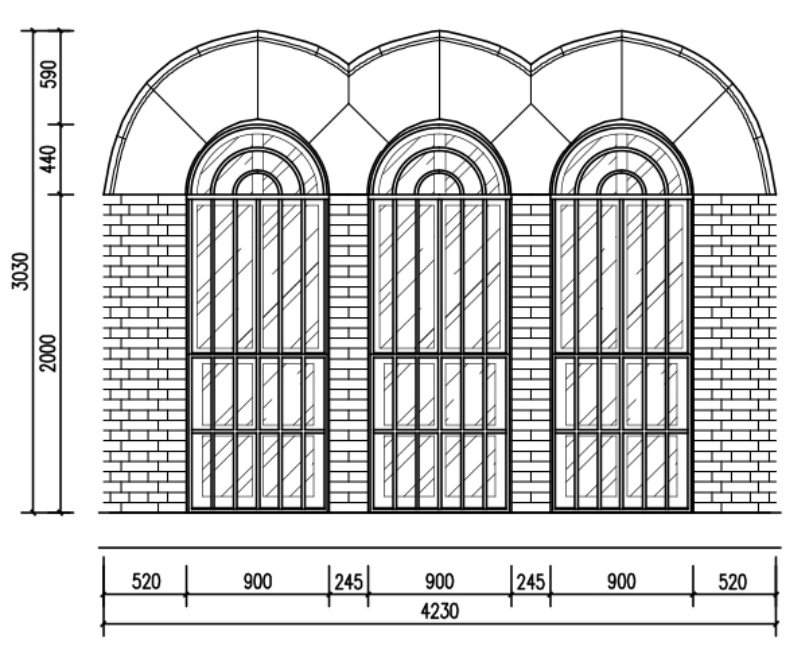

Figure 3. One of the exterior windows of Zhongshan Square No. 2

Zhongshan Square No.2 is the only building with additional constructions in Zhongshan Square. After renovation in 2002, many structures were added to the facade to protect the building. However, due to the large building volume and complex users, the overall reuse situation is not good, especially the exterior windows.

According to the survey, the windows were all made of modern plastic steel. The Gothic long window is divided into three parts, and the bottom window is made into awning window for ventilation. Although this method of reuse satisfies people's needs, such a crude division of windows cannot show the characteristics of Gothic lattice windows, which flattens the facade of the building. Emulsion paint was sprayed on the lintel of the exterior window in the process of repair, but plenty of it fell off or damaged because of being exposed to wind and rain for a long time. Some wall covers that are easy to drop off are not only unsightly, but also pose a threat to the safety of pedestrians. In addition, the dense and imprecise green paint fences added have restricts the vertical movement of the exterior windows, and weakened the sense of refinement of the building facade. 


\subsection{Zhongshan Square No.4}

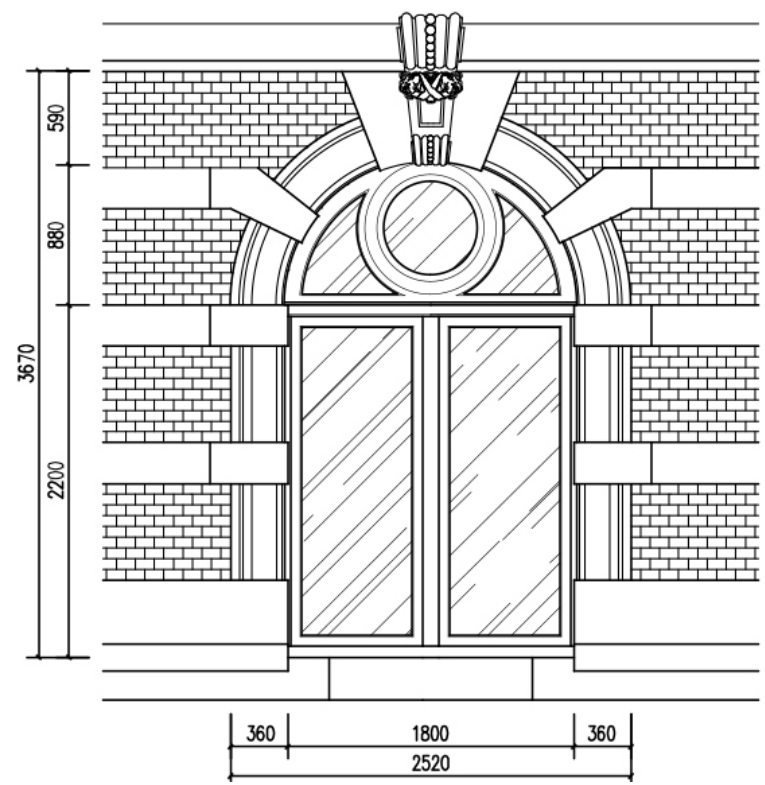

Figure 4. One of the exterior windows of main façade of Zhongshan Square No.4

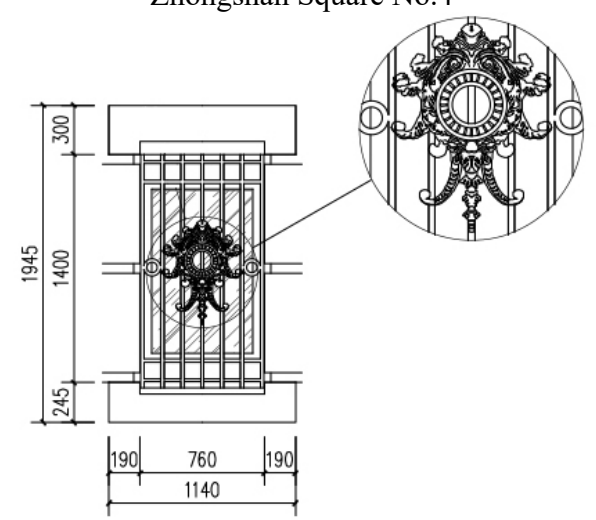

Figure 5. Decorative fence of the exterior windows of Zhongshan Square No.4

Zhongshan Square No.4 is the building with the highest degree of original appearance among the all the buildings. On the whole, the architectural details are kept to a high degree, and various decorative patterns on the exterior windows are clearly visible. Since the surface of stones have not been painted with rock varnish, the traces of history on the surface of the stone are also preserved, which fully reflects the sense of age. In addition, the frames are painted in dark green to create a conflict with the pale red brick wall, and the transition is decorated with light gray marble to form a sense of conflict and harmony, which is also an interpretation of the Baroque style ${ }^{[2]}$. However, through research, it is found that the buildings still retain the old wooden windows. Although the decoration is exquisite, the window is too old and no longer has the original function. The windows in the past are all made of single-layer glass, which has a poor thermal insulation effect and cannot meet the needs of hotel residents. Therefore, the hotel uses thermal insulation materials to seal the windows so that the windows cannot be opened, which greatly reduces practical functions.

\subsection{Zhongshan Square No.6}

Zhongshan Square No.6 is one of the large buildings. It adopts a three-stage design as a whole. It was used as an office building at that time and now it is a bank. The current situation of the reuse of the building is relatively good, and the windows are all replaced with modern windows, which is a case of a perfect combination of modern and classical styles.

The bottom floor of the building is arched window, which is characterized by classical rigorous geometric composition. In the process of reuse, the slenderness of the original arched long window is retained by dividing the plastic-steel window horizontally and vertically. The white plastic steel windows are harmonious with the milky white marble of the original building, and the golden carving on the fence enriches the details of the outer windows, making the modern windows perfectly combined with the old buildings ${ }^{[3]}$.

In terms of function, the improved plastic steel window adopts the way of opening inward, and the screen window is set outside to meet the needs of ventilation and mosquito prevention. After division, only two sashes window that can be opened are left in the large arched long window to ensure the indoor thermal insulation effect.

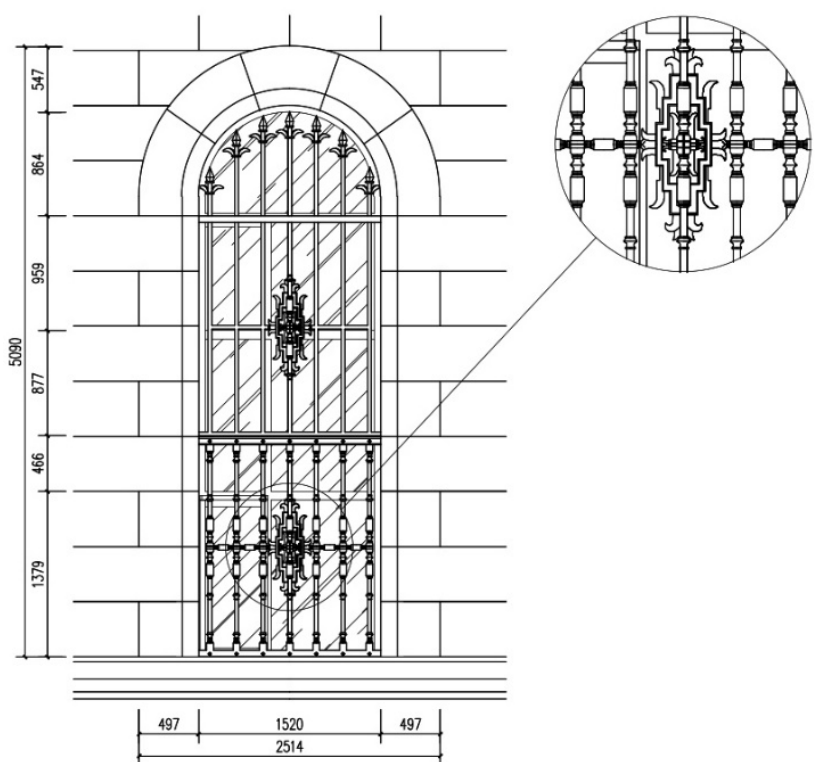

Figure 6. The arched long windows of Zhongshan Square No.6

\subsection{Zhongshan Square No.7 and No.9}

Zhongshan Square No. 7 and No. 9 are two buildings with relatively simple outer windows. In the process of reuse, the exterior windows are not excessively changed or added, the window frames and the building itself are also very integrated, and the overall facade style is the continuation of its original architectural style.

In terms of handling exterior windows, Zhongshan Plaza No. 7, like most buildings in the building group, uses rock varnish to keep its surface clean and tidy, but many problems are exposed in the subsequent use and learning.

Through the investigation, it is found that due to the weak combination between rock varnish and the stone 
surface, there are a large number of exfoliated parts in the decorative frame of Zhongshan Square No. 7, which was simply repaired with cement, so the delicacy of the outer window is greatly reduced.

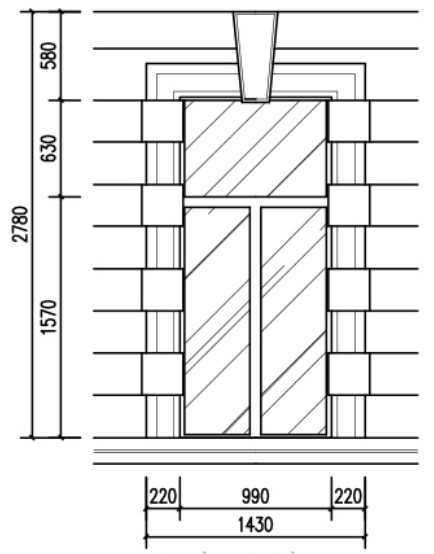

Figure 7. Exterior windows of Zhongshan Square No.7

Zhongshan Square No. 9 chose to spray white latex paint on the exterior windows to highlight the decorative structures such as decorative frames and moldings of the exterior windows. Compared with the rough surface of rock varnish, the smoother surface of latex paint is not easy to accumulate dust, but which also makes it difficult to keep the frame clean ${ }^{[4]}$.

In terms of function, part of the exterior windows of the two buildings have been converted into fixed windows. At the same time, internal shading is adopted to retain the integrity of the facade effect and meet the bank's safety requirements.

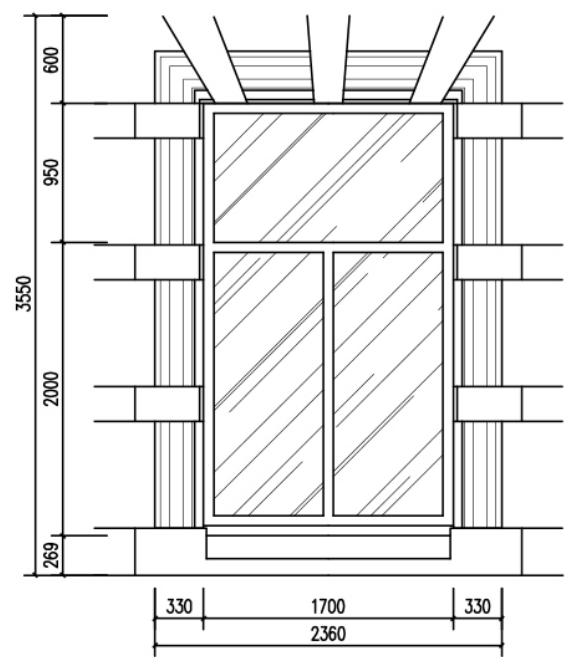

Figure 8. Exterior windows of Zhongshan Square No.9

\subsection{Zhongshan Square No.10}

Zhongshan Square No. 10 is the one that has a poor reutilization status. The renovation of exterior windows is now in a serious state of decay, which reduces the overall quality of exterior windows and cannot meet the needs of people's life. At the same time, the bright blue in the stained glass is not harmonious with the eclectic facade.

In addition, the fence added to the outer windows on the first floor is completely different from the fences of the high windows in the basement in form and color, which makes the exterior window elements mixed and affects the unity and harmony of the building facade.

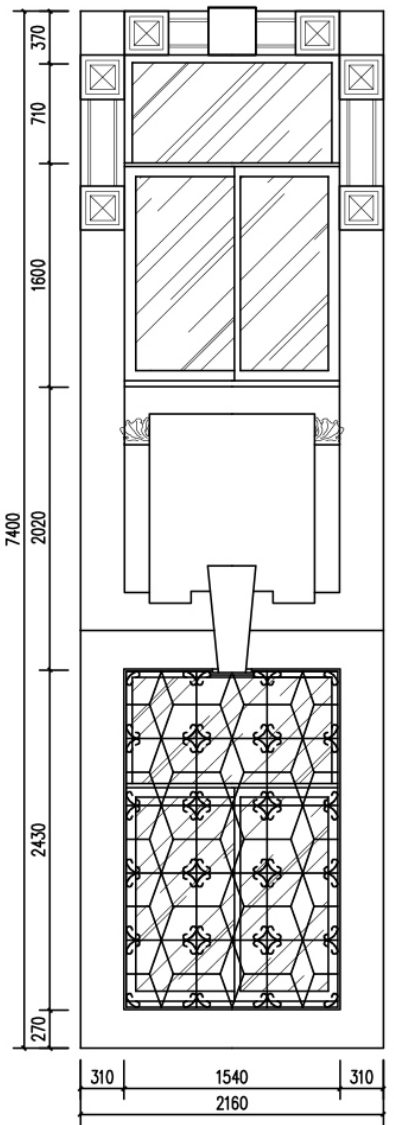

Figure 9. Stained glass of the exterior windows of Zhongshan Square No.10

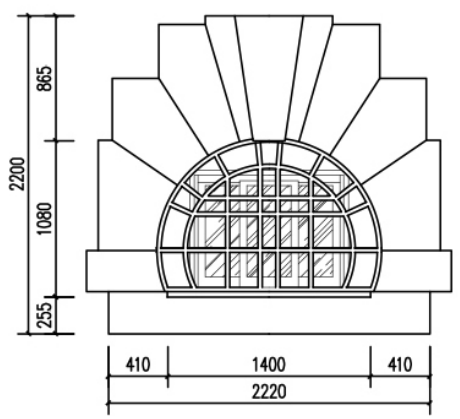

Figure 10. Decorative fence of the exterior windows of Zhongshan Square No.10

\section{Conclusion}

As one of the important parts of historical building details, exterior windows play an important role in both practicability and decoration. In the process of reusing the exterior windows of Zhongshan Square historical building group in Dalian, the reuse of the exterior windows of buildings with different architectural styles and ways of use is quite different, but on the whole, it presents a good state. After investigating several representative buildings, we summarized and sorted out the problems caused by the exterior windows in the process of reuse, mainly in the following aspects:

First of all, the added and rebuilt components conflict with the original facade, which only meets the functional 
requirements and ignores the overall aesthetic integration. Secondly, some of the windows directly use the original structure without transformation, which makes it unable to meet the requirements of people's daily life. Thirdly, the spraying material on the outer window frame did not achieve the expected effect. On the contrary, it is inferior to the original decorative effect of stone surface. Fourthly, inadequate maintenance and protection of exterior windows caused frequent occurrence of various problems. It can be seen that there is still a lot of room for improvement in the ways and methods of reusing the exterior windows. It is hoped that this research can attract the attention of relevant departments so that the protection of historical buildings and the use of people can form a balance, and finally a better level of reuse can be achieved.

\section{References}

1. Zhao Yanhui (2011) Research on Status and Prospects of Reuse of Modern Historic Buildings in Dalian Taking Modern Public Building in Zhongshan Square and Circumjacent as an Example, Master Thesis of Dalian University of Technology.

2. Wang Shiyuan,Liu Beibei,Xu Weixing, Liu Jiuju(2020)Study on the Value Evaluation of Modern Historic Buildings — A Case of Zhongshan District in Dalian, Urbanism and Architecture,348:170-174.

3. Sui Qingxi,Zhang Fuhe, Cun Songshen(1995)The Architectural Heritage Of Modern China —_ Dalian, China Architecture \& Building Press.

4. S.Cantancuzino(1975)New Use for Old Buildings,Architectual press,London. 